39. Teare EL, Cookson B, French GL, Jenner EA, Scott G, Pallett A, et al. UK handwashing initiative. J Hosp Infect 1999;43:1-3.

40. Larson EL, Bryan JL, Adler LM, Blane CB. A multifaceted approach to changing handwashing behavior. Am J Infect Control 1997;25:3-10.

41. Weeks A. Why I don't wash my hands between each patient contact. BMJ 1999;319:518.

42. Harbarth S, Sudre P, Dharan S, Cadenas M, Pittet D. Outbreak of Enterobacter cloacae related to understaffing, overcrowding, and poor hygiene practices. Infect Control Hosp Epidemiol 1999;20:598603.

43. Preston GA, Larson EL, Stamm W. The effect of private isolation rooms on patient care practices, colonization and infection in an intensive care unit. Am J Med 1981;70:641-645.

44. Larson E. Compliance with isolation technique. Am J Infect Control 1983;11:221-225.

45. Pettinger A, Nettleman M. Epidemiology of isolation precautions. Infect Control Hosp Epidemiol 1991;12:303-307.

46. Iarson EL, McGinley KJ, Foglia A, Leyden JJ, Boland N, Larson J, et al. Handwashing practices and resistance and density of bacterial hand flora on two pediatric units in Lima, Peru. Am J Infect Control 1992;20:65-72.

47. Zimakoff JD, Pontoppidan B, Larsen SO, Poulsen KB, Stickler DJ. The management of urinary catheters: compliance of practice in Danish hospitals, nursing homes and home care to national guidelines. Scand J Urol Nephrol 1995;29:299-309.

\title{
Proposed Tuberculin PPD-S2 as Reference Standard
}

\section{Gina Pugliese, RN, MS Martin S. Favero, PhD}

Since 1951, the tuberculin PPD-S1 has been used to standardize commercial PPD reagents and perform special tuberculin surveys. PPD-S1 is now in short supply, and a new standard (PPD-S2) has been manufactured. To determine if PPD-S2 is equivalent and can replace PPD-S1, Villarino and coinvestigators from the CDC; the FDA; Seattle-King County Health Department, University of California, San Diego; University of Arizona, Tucson; Emory University, Atlanta, Georgia; Marion County Health Department, Indianapolis, Indiana; and
Denver Public Health Department, Denver, Colorado, conducted a doubleblind clinical trial. Between May 14 and October 28, 1997, 69 subjects with a history of culture-proven TB (TB patients) and 1,189 subjects with a very low risk for $\mathrm{TB}$ infection were enrolled, received four skin tests (with PPD-S1, PPD-S2, and one each of the commercially available PPDs), and had reactions measured by two trained observers. Among the TB patients, there was statistically indistinguishable immunogenicity (mean reaction size \pm standard deviation): $15.6 \pm 6.6 \mathrm{~mm}$ for PPD-S1 and $14.8 \pm 5.6 \mathrm{~mm}$ for PPD-S2. Among low-risk subjects, the tests had equally high specificities (PPD-S1, 98.7\%; PPD-S2, 98.5\%), using a 10-mm cutoff. The number of discordant (negative vs positive) interpretations for PPD-S2, assuming that low-risk subjects who had $a \geqslant 10 \mathrm{~mm}$ reaction to PPD-S1 were truly infected, was low $(0.5 \%)$ and indistinguishable from the rate of discordant interpretations of the same test when read by two different observers $(0.8 \%)$

The study results indicate that PPD$\mathrm{S} 2$ is qualified to be used as the new US reference standard for PPD tuberculin.

FROM: Villarino ME, Brennan MJ Nolan CM, Catanzaro A, Lundergan LL, Bock NN, et al. Comparison testing of current (PPD-S1) and proposed (PPD-S2) reference tuberculin standards. Am J Respir Crit Care Med 2000;161 (4 part 1):1167-1171. 